\title{
CORPUS Corpus
}

Archivos virtuales de la alteridad americana

Vol 2, No 2 | 2012

Julio / Diciembre 2012

\section{Evangelización franciscana en Araucanía:El catecismo de Serviliano Orbanel}

Franciscan Evangelization in the Araucania: The Catechism by Serviliano

Orbanel

Marisa Malvestitti and María Andrea Nicoletti

\section{OpenEdition}

\section{Journals}

Electronic version

URL: http://journals.openedition.org/corpusarchivos/867

DOI: $10.4000 /$ corpusarchivos.867

ISSN: $1853-8037$

Publisher

Diego Escolar

Electronic reference

Marisa Malvestitti y María Andrea Nicoletti, « Evangelización franciscana en Araucanía:El catecismo de Serviliano Orbanel », Corpus [En línea], Vol 2, No 2 | 2012, Publicado el 30 diciembre 2012, consultado el 05 mayo 2019. URL : http://journals.openedition.org/corpusarchivos/867 ; DOI : 10.4000/corpusarchivos.867

This text was automatically generated on 5 May 2019.

Licencia Creative Commons: Atribución-NoComercial 2.5 Argentina (CC BY-NC 2.5 AR) 


\section{Evangelización franciscana en Araucanía:El catecismo de Serviliano Orbanel}

Franciscan Evangelization in the Araucanía: The Catechism by Serviliano

Orbanel

Marisa Malvestitti and María Andrea Nicoletti

\section{EDITOR'S NOTE}

Fecha de recepción del original: 18/09/2012. Fecha de aceptación para publicación:

01/11/2012

Agradecemos a los bibliotecarios del Museo Mitre de la ciudad de Buenos Aires: Maximiliano Ariel Rodríguez y María Ximena Iglesias.

Dedicado al P. Meinrado Hux, in memoriam

\section{Introducción}

1 En la historia de la evangelización americana, tanto en la etapa colonial como en la de los Estados nacionales, el análisis de las prácticas de comunicación de la doctrina cristiana y la administración sacramental constituyeron un tema clave para comprender las relaciones entre indígenas y misioneros en el complejo contexto de las conquistas, signadas por la violencia, la distribución diferencial del espacio y la reorganización de las relaciones entre los distintos actores sociales.

2 Los planes misioneros fueron elaborados en términos teóricos, en base a una construcción de alteridad del sujeto de evangelización: la idea del "infiel”, que resultó determinante en el acercamiento a los indígenas excluidos del modelo colonial y nacional. En medio de la 
violencia material de la conquista, "el ejercicio de esta 'violencia pacífica' o simbólica supone un conocimiento exhaustivo del sujeto por civilizar (creación de un nuevo tipo de saber) y la elaboración de estructuras cognitivas o disposiciones (habitus) adaptadas a un nuevo campo o espacio social, o sea la misión. Este tipo de poder-saber que pretende penetrar la realidad indígena para transformarla desde el interior e interiorizar la transformación, supone la existencia de una nueva mirada puesta sobre el indígena" (Boccara, 2003, p. 283). Sin abandonar el estereotipo del "salvaje", los misioneros de las distintas ordenes que evangelizaron América resignificaron esta imagen sosteniendo su núcleo duro e inclinando de esta manera la balanza hacia la protección, el paternalismo y su propia acción mediadora, "secularizando su rol" (Boccara, 2003, p. 363) y reforzando la subalteridad aborigen. En ese estatus, el sujeto adoctrinado y bautizado pasaba a ser "indígena converso", nunca del todo equiparable al "converso", pues siempre se reforzaba en la palabra indígena la situación previa de "infidelidad" y la situación subalterna de "minoridad". Esta situación jugó un rol fundamental en el concepto de su "capacidad" para la asimilación de la nueva religión.

3 Los textos catequísticos se plantearon entonces para enseñar a "todos los indios conforme a su capacidad", "regulando la consistencia del alimento que sus hijos espirituales están capacitados para asimilar", haciéndolo con paciencia, caridad y perseverancia, reiterándoles repetidas veces los puntos fundamentales de la fe de forma breve, clara y sencilla hasta que la comprendieran y la supieran de memoria (Durán, 1990, pp. 625-627). Esta adaptación constituyó una necesidad entendida por la Iglesia no sólo en la traducción de la doctrina a lenguas vernáculas, sino también en su adecuación, por medio de diferentes instrumentos, fundamentalmente los catecismos, adaptados según los misioneros a la "capacidad de los infieles".

4 La adaptación de la doctrina a lenguas indígenas supuso no sólo aproximarse a las culturas y lenguas de los pueblos originarios, sino adentrarse fundamentalmente en sus religiones, para poder tomar de ellas términos equivalentes y catalogar todo lo que, de acuerdo a la comparación con la doctrina cristiana, caía bajo el concepto de idolatría, superstición y pecado ${ }^{1}$.

5 El conocimiento y dominio de la lengua de los sujetos de evangelización permitió crear y hacer circular discursos religiosos que buscaron homogeneizar y controlar al otro mediante categorías que rigen la relación entre lo humano y lo divino. La lengua jugó un papel preponderante para la transmisión y la imposición de la fe católica. El impacto cultural que produjo la primera evangelización americana fue de tal magnitud que replanteó, en función del alcance de la prédica de la doctrina, la relación y la comunicación entre los misioneros y los pueblos originarios.

6 En este trabajo presentamos una fuente inédita de la orden franciscana del siglo XVIII empleada para la evangelización del pueblo mapuche: la Doctrina cristiana, catecismo, forma de administrar los sacramentos con 22 pláticas en araucano compuesta por Fray Serviliano Orbanel (circa 1778) cuyo manuscrito se encuentra en el Archivo del Museo Mitre (CABA). Se trata de un conjunto de textos para adoctrinar indígenas en su lengua y administrar los sacramentos de la Iglesia católica, redactado en mapuzungun, español y latín que funcionaba presumiblemente como una guía o manual para el misionero. El llamado "catecismo de Orbanel", por su autoría franciscana, fragmenta el monopolio jesuita de producción catequística bilingüe en mapuzungun, y si bien la fuente dialoga con ésta, también presenta aspectos particulares que serán el objeto de este análisis. 


\section{Evangelizar en "lengua de los naturales": textos catequíticos bilingües}

7 La diversidad de lenguas indígenas, sumadas al latín y al español, presentaba un serio obstáculo a la hora de la transmisión de las verdades de la fe católica. Era pues necesario y urgente redactar catecismos adaptados a las circunstancias. Por ello, el Concilio III Limense (1584-85)", "manda a los obispos que provean a los indios de confesores que puedan escucharlos y entenderlos pese a la diversidad de las lenguas y ordenan que si no entienden bastante al que se confiesan, remítanle a otros que sepan más o aprendan ellos lo que no saben y establecen un examen obligatorio en doctrina y en lengua para los curas de indios" (García y García, 1986, p. 196). Las cátedras de lenguas de los naturales en los seminarios conciliares de América fueron creadas por Felipe II en 1580 y 1591, pero el hito fundamental que abrió la posibilidad de catecismos en lenguas vernáculas para América fue el III Concilio Limense, que tradujo sus catecismos al quechua y aymara (1583). Esos catecismos continuaron utilizándose hasta el Concilio Plenario Latinoamericano de 1899.

El primer paso que debía seguir un misionero para lograr finalmente predicar la fe en lengua nativa era aprenderla, generalmente por contacto directo mediante lenguaraces o por medio de los diccionarios, gramáticas y catecismos que circulaban en los seminarios conciliares. También consultaba los "vocabularios" que tras su adaptación gramatical concluían en la redacción de los llamados "artes" y gramáticas". "Recién entonces estuvieron en condiciones de predicar la fe cristiana en forma oral y volcar su contenido en la escritura alfabética" (Durán, 1982). De allí surgían diferentes instrumentos para la prédica de la fe: la versión de las oraciones usuales a las lenguas vernáculas; los catecismos "mayores" y "menores", que consistían en la articulación de la fe adaptada a las "capacidades" indígenas; los complementos pastorales del catecismo, que educaban en los aspectos litúrgicos y sacramentales como los "confesionarios", la "exhortación para ayudar al bien morir", los "impedimentos del matrimonio" o los "Sermonarios", que eran una selección de sermones o prédicas para ministros sobre temas doctrinales y morales.

El objetivo planteado por el III Concilio Limense fue el de la unificación de la diversidad doctrinal, de contenido, de lenguas y de catecismos o cartillas circulantes en lenguas vernáculas en el entonces Virreinato del Perú, bajo cuya órbita se encontraba el reino de Chile. Doctrinariamente el Catecismo Limense se inspiró en el Catecismo tridentino o de San Pío V que también buscaba unificar la doctrina e imprimir un texto único y oficial (1563-66). Como señala Durán (1982), los Catecismos del Concilio Limense siguen una metodología de preguntas y respuestas para facilitar el ejercicio memorístico, graduación en la presentación de las verdades cristianas (catecismo breve y catecismo mayor) y la traducción a las lenguas vernáculas, prohibiendo el uso del latín y el castellano para los indígenas, pero permaneciendo estas lenguas para uso del misionero. En este último punto cada obispo debía procurar la traducción del catecismo en la lengua vernácula de su jurisdicción y le competía la aprobación de los textos.

10 En el contexto del III Concilio Limense se realizó la traducción del catecismo a la "lengua del Obispado del Reino de Chile", o sea del mapuzungun, con la aprobación de los obispos Diego Medellín y Antonio de San Miguel. Este catecismo fue el que Luis de Valdivia corrigió y llevó a la imprenta quedando inserto en su obra Arte y Gramática General de la Lengua (1606). Los primeros catecismos en mapuzungun fueron producidos por la Orden jesuita para la evangelización de la zona de la Araucanía. Otros textos de gran circulación 
fueron el Arte de la Lengua General del Reyno de Chile de Andrés Febrés (1765) y Chilidúgú de Bernardo Havestadt (1777). Estas obras circularon ampliamente por las regiones en las que se hablaba mapuzungun, constituyendo una fuente innegable de publicaciones posteriores del mismo tipo.

Los franciscanos evangelizaron en el reino de Chile a partir de 1553, realizando sus primeras fundaciones en Santiago. La segunda fundación fue ese mismo año en la ciudad de Concepción, expandiéndose hacia la Araucanía. Ese mismo año Pedro de Valdivia fue muerto en Tucapel y los franciscanos regresaron a Santiago. Mientras avanzaba la conquista, iban avanzando también las fundaciones franciscanas (Nuestra Señora de los Remedios en la ciudad de Valdivia, Nuestra Señora de la Buena Esperanza, en la ciudad de La Serena en 1562; Santa María de los Ángeles de la ciudad de Angol en 1567; San Francisco de Jesús, en la ciudad de Imperial en 1568; Nuestra Señora de las Nieves en Villarica; San Francisco en Castro en 1568, convento de Copiapó y de San Diego en Santiago en 1660). En los siglos XVI y XVII los franciscanos ocuparon sedes episcopales del entonces Reino de Chile (Santiago y la Imperial - Concepción), y tras la expulsión de los jesuitas en 1767, se hicieron cargo del conjunto de misiones desde Concepción hasta Osorno.

12 En el proceso de evangelización, jesuitas y franciscanos mantuvieron en la Araucanía diferencias respecto del concepto de adoctrinamiento y de administración del bautismo y posturas encontradas en torno a la percepción de los indígenas y las diferencias culturales que los separaban. Frente a la resistencia mapuche de conquista del territorio los jesuitas optaron por la salvación mediante la administración del sacramento del bautismo, hubiese sido o no asimilada la doctrina, ya que estaban seguros de que la gracia santificante accionaba en la salvación de las almas. Los franciscanos consideraban necesario un adoctrinamiento previo. No compartieron con los jesuitas la administración del sacramento de forma inmediata sosteniendo una posición más estricta ante el conocimiento de las verdades de la $\mathrm{Fe}^{3}$. Pero los jesuitas, hicieron un importante esfuerzo en el adoctrinamiento en lengua, que no realizaron los franciscanos, temerosos de que la traducción desvirtuara la doctrina de la fe considerada verdadera.

Tras la expulsión de los jesuitas en 1767, los franciscanos se hicieron cargo de la evangelización a uno y a otro lado de la cordillera (Holdenis Casanova, 1988). Chillán va a ser clave en la evangelización transcordillerana; formaba parte de un grupo de colegios de Propaganda Fide ya fundados en Portugal, México, España y Perú. Su fundación se verá dos veces frustrada. Promovida desde la Corona en 1692, duró apenas cinco años, igual que en 1729. Sin embargo, en el tercer intento, en 1756, estudiado el lugar propicio y fundado por frailes experimentados en Colegios Propaganda Fide, su sede quedó en Chillán. Ello se debe a la expansión paulatina de su actividad misionera al sur del Bío Bío. Chillán es un "laboratorio misional" en el que los frailes eran preparados para esta labor. Durante los diez primeros años no se les permitía la vuelta a su provincia o el cambio a otra. Cumplido ese plazo, podían retirarse todos aquellos que no se encontrasen en condiciones de afrontar las exigencias psíquicas y físicas de la vida misionera.

El interés por evangelizar a los pehuenches durante el siglo XVIII formó parte de las intensas relaciones fronterizas vividas a través de la cordillera, y de la política de paz y población que forman parte del siglo XVIII. El gobierno de Amat y Junient, que tenía una especial predisposición por los franciscanos, les adjudicó las misiones al Colegio de Chillán, a propósito del parlamento celebrado en el Salto de la Laja (1756) en el cual los indígenas pedían patirus caris (padres grises). De esta manera las misiones pasaron a ser 
una fuerza más para afianzar las relaciones entre españoles e indígenas: comerciales, sociales, culturales y de alianzas bélicas.

Hacia el período independiente, el gobierno chileno interesado en la continuidad de las misiones, envió a Roma, en 1836, a fray Zenón Badía, franciscano argentino, con el propósito de conseguir misioneros para la Araucanía. En 1837 llegaron trece frailes italianos a Valparaíso para retomar las misiones del sur desde el Colegio de Propaganda Fide de Chillán. La preocupación del Estado chileno por la continuidad de estas misiones los llevó nuevamente a gestionar en 1847 la incorporación de más frailes a las misiones. De este modo, otra orden mendicante, los capuchinos, llegó a Chile en 1848. Fray Ángel Vigilio de Lonigo organizó un grupo de unos 11 capuchinos italianos y un bávaro, que se instalaron en la frontera sur del río Cautín, quedando así delimitadas las zonas de evangelización entre ambas ordenes para evitar conflictos que ya se habían suscitado (Pinto Rodríguez, 1993, pp. 38-47) .

Durante este período el franciscano fray Antonio Hernández Calzada hizo una nueva publicación del texto de Febrés en 1846, que junto con la edición abreviada de 1864, también se divulgó en el ámbito pampeano. A la vez, compuso un extenso confesionario, que circuló manuscrito hasta su publicación en 1907.

Del otro lado de la cordillera, en el área ranquelina, las misiones franciscanas formaron parte de la estrategia para "pacificar" a los indígenas en la zona de Río IV (Tamagnini y Pérez Zavala, 2011, p. 208-220), a pedido de los vecinos de la Villa para "la pacificación y contención de los ranqueles". En medio siglo llevaron adelante actividades de "educación, tareas de evangelización, la promoción humana, el rescate de cautivos, las negociaciones por la paz, las relaciones entre militares, gobierno e indios ranqueles y la atención del Curato" (Farías, 2006). Si bien los misioneros eran conscientes de que comprender y hablar las lenguas originarias era central para el éxito del adoctrinamiento, se sentía la ausencia de materiales adecuados para el aprendizaje. Según Pérez Zavala (2005), hacia la década de 1870 los franciscanos Moisés Álvarez y Marco Donati lograron conseguir la Gramática de Febrés ${ }^{5}$, y con ella comenzaron el estudio de la lengua (Durán, 1997, pp. 5-69). La práctica de estos dos misioneros no parece haberse extendido a sus hermanos, ya que por ejemplo, el padre Bentivoglio, capellán de la Tercera división del Ejército al mando de Racedo que incursionó en el área ranquel, reconocía no poder desempeñarse en la lengua (Racedo, 1965, p. 236).

De este modo puede observarse un circuito de difusión de este tipo de materiales para el que la cordillera no operó como un obstáculo, así como pueden reconocerse claras relaciones intertextuales establecidas entre las producciones de quienes llevaron adelante su práctica misional en el ámbito territorial mapuche.

\section{El catecismo de Orbanel: presentación y estructura del texto}

\subsection{Presentación}

La fuente que analizamos en este trabajo tiene sólo dos referencias previas. Tuvimos conocimiento de ella mediante la mención del padre Meinrado Hux (Hux, 2000, p. 101), que la cita como: "Orbanel, Serviliano Fray, Doctrina cristiana, catecismo, forma de administrar los sacramentos con 22 pláticas en araucano. 1778. Mnsr, en Museo Mitre, Bs. 
As", y la ubica en el apartado C.3. de su catálogo titulado Catecismos para indios o doctrinas cristianas, junto a los catecismos de Valdivia, Augusta, Savino, Birot, y algunos artículos de análisis sobre el tema. La otra referencia aparece en el Catalógo razonado de la sección Lenguas americanas de Bartolomé Mitre. En este se publicaron las fichas que el propio Mitre confeccionó para dar cuenta del fondo bibliográfico que componía su colección; las mismas actualmente pueden ser consultadas en el Archivo del Museo Mitre. Aquí, en la sección III "Araucano", se ingresa la referencia al texto de la siguiente manera: "22. ORBANEL (F. Serviliano), Doctrina Christiana, Catecismo, forma de administrar los Sacramentos, y otras instrucciones necesarias para los Misioneros de Arauco, con 22 pláticas en Araucano y un tratado sobre transiciones, gerundios y participios en la misma lengua. - Manuscrito original inédito. (Circa, 1778). 8o esp. Port. y 159 ff" (Mitre 1909, T. I, p. 326).

La referencia de Mitre describe de manera más completa el texto, ubicando el contexto de producción en Araucanía y estimando la fecha de producción del mismo después de 1778, es decir posterior a la expulsión de América de la orden jesuita. En el desarrollo de la ficha, señala que el manuscrito había pertenecido "a la colección de don Pedro de Ángelis" y que el título que le asigna "es facticio, pero conforme a su contenido y al índice original” (Mitre, 1909, T. I, p. 327).

21 Nos comunicamos con el padre Hux en septiembre de 2008 luego de acceder a la biblioteca del Museo Mitre y haber podido fotografiar el manuscrito. Le enviamos el documento y le solicitamos ayuda para la traducción del texto en latín de la página final. Este documento se presenta en el PDF anexo. El padre Meinrado generosamente nos acercó una primera traducción de ese texto. El mismo fue analizado también por las investigadoras Prof. Dora Battiston y Carolina Domínguez, del Instituto de Estudios Clásicos de la Facultad de Ciencias Humanas de la UNLPam, quienes además proveyeron versiones al español de otros fragmentos en latín del texto. De sus lecturas puede conformarse la siguiente versión del folio final: Pertinet ad vsum Patris Josefi a Patiño regularis observanciae Serafici Patris Nostri Fran[cisci] hujius Cenovi Purissimae Conceptionis, en español "Se destina al uso" del Padre José, de (parte de) Patiño de la regular observancia de Nuestro Seráfico Padre Francisco, cuyo convento es la Purísima Concepción". A continuación, la firma "Patiño" aparece dos veces y rubricada. Hux propone considerar a José Patiño como un franciscano radicado en la ciudad de Concepción, en la Araucanía. Esta interpretación de procedencia geográfica es avalada por una mención en el f. 46 a Fray Pedro Ángel, obispo de la Concepción, fallecido en $1778^{8}$. Los franciscanos fundaron, el 11 de noviembre de 1553 en la ciudad de Concepción, el convento de la Purísima Concepción de la Virgen María. Battiston y Domínguez, por su parte, aclaran la correspondencia de "orden seráfica" con la franciscana, ya que ese era uno de los apelativos con que se denominaba al fundador de la orden, San Francisco de Asís9, y explican la indicación "de la regular observancia"10.

Siendo José Patiño el poseedor del manuscrito, quedaba pendiente la asignación de autor, que tanto Mitre como Hux relacionaban con Fray Serviliano Orbanel. Mitre lo justifica indicando una leyenda que se observa "en el anverso de la foja 157, a cuyo dorso empieza el Indice de su misma letra", a la que denomina "Protestación": "Protesto y declaro que todo cuanto he escrito en este Cuaderno Indico, lo ofrezco y sujeto con toda humildad y veneración y corrección de Nuestra Sta Me Iglea Catholica Romana, que es Columna de la Fe y Firmamento de la Verdad y al juicio también de todos aquellos qe por autoridad de la misma Iglea tienen facultad para censurar Doctrinas. Si alguna proposición hubiese puesto que disuene a la enseñanza y espíritu de la Sta Iglea desde ahora la retrato, detesto 
y abomino, dándola por no escrita. Fr. Serviliano Orbanel...". No ha sido posible recuperar otros datos biográficos sobre el mismo.

Retitulada Rezos en chileno, sin indicación de autor, la fuente fue encuadernada como libro en tamaño octava. Para ello el tamaño de las páginas fue recortado respecto del original y en algunos folios los márgenes se vieron reducidos. Ordenado de manera escrupulosa ${ }^{11}$, con numeración de páginas sucesivas en la parte superior de la página derecha, solo presentan problemas de presentación secuencial las últimas páginas del manuscrito (fs. 156-158). Es además clara en su estructura paratextual, con títulos y subtítulos que presentamos más abajo. En cuanto a las grafías, pueden asignarse a más de una persona. Proponemos que una de ellas corresponde a Serviliano Orbanel, dado el uso de la primera persona en la Protestación; la otra, a José Patiño, quien firma la pertenencia del manuscrito en la página final.

Redactado en mapudungun, latín y español, el texto cambia a uno u otro código según la función asignada a cada uno o la pretensión de legibilidad en cada caso. Así, los paratextos (títulos, índices) y las notas aclaratorias o directivas aparecen en castellano; los textos litúrgicos y destinados a la evangelización (oraciones, mandamientos, catecismo, confesionario y pláticas) están versionados al mapudungun, ya que se preveía utilizarlos en eventos en los que primaría esa lengua. En latín aparecen las respuestas que en esa lengua dará el sacerdote, los segmentos litúrgicos que se enuncian en esa lengua, y por ende no se versionan a la lengua originaria, y algunos contenidos de la confesión o las pláticas relativos a la moral sexual que el sacerdote pregunta en la lengua de la Iglesia, o bien menciona como comentarios dirigidos al usuario del manual. Veáse para el primer caso el siguiente ejemplo:

\section{f. 12. A la Puerta de la Iglesia}

Pregunta. Chem gillapakeimi Iglesia meu? [¿qué vienes a pedir a la Iglesia?]

R. Ñi christiano geam. [ser cristiano]

P. Chem cam ta hueuaimi tami Christiano gen meu? [Qué ganarías al ser cristiano?

[...]

Sac. Hoc est autem vita et a. U. [Esa es la vida verdadera y etc.]

En otro ejemplo, se detalla la primera parte de la "Fórmula para aplicar indulgencia plenaria a los indios que están en el artículo de muerte", según la versión aplicada en Concepción en 1777 por el Obispo Pedro Ángel de Espiñeira. El texto está en latín, y las siglas de inicio indican, $\mathrm{V}$ (de vox, o vocat), una abreviatura que refiere a la enunciación del sacerdote, y R., Responsa [populus respondet], es decir la 'respuesta' de los fieles; en tanto que Ana. es la abreviatura de Antiphona, que marca el inicio de los siete salmos penitenciales: \& es un símbolo que indica que se presupone la continuación de una fórmula ya conocida (Battiston y Domínguez, c.p.).

f. 46. V. Adjutorium nostrum $\&^{12}$. R. qui $\&^{13}$

Ana. Ne reminiscaris Dne..$^{14}$ delicta Famuli tui (vel Ancilla tua) neque vindicta sumas

de peccatis eius. Kyrie eleyson ${ }^{15} \&$ Patr. Nostr.

V. Et ne nos $\&^{16}$. BC. Sed \&. ${ }^{17}$

V. Salvum fac servum tuus (vel Ancillam tuuam)

Rf. Deus meus sperantem in te.

V. Dno. exaudi orationem meam.

Rf. Et clamor meus \&.

V. Dominus vobiscum.

Rf. Et cum \&. ${ }^{18}$

Oremus 
La práctica continúa en latín y, luego de finalizar, reza la aclaración en español en f. 47 b: «Nota: Si el enfermo estuviere tan cerca a la muerte que no haya tiempo ni para decir la confesión general ni para rezar las preces sobre detrás, dele el sacerdote inmediatamente la bendición».

De modo similar, en f. 34 b correspondiente al sexto mandamiento de la confesión, se observa el título en castellano "A la mujer", tres preguntas en mapuzungun acerca de si ha tenido ocasiones de aborto, mal parto o infanticidio, y una observación final en latín en la que se recuerda el sacerdote hacer este interrogatorio con suma prudencia, de modo de no causar escándalo en los fieles, ni desconfianza por la práctica de la confesión.
f. 34b. A la Muger
P. Putuimi chey quiñe lahuen tañi piñeñnoal, tañi wera coñial chey?
P. Huera coñimi chey?
P. Lagümvimi chey mi piñeñ, tami quimmagenoavuel mu huerin?
Catena interrogaciones, sicut hominibus, mutatis mutandis; sed utriusque magna cum cautela et prudencia; ne vel scandalicentur, vel de confesario male suspicentur; ad quom quantum rudiores, tantum faciliores, et promptiores sunt.

\subsection{Estructura}

Para el análisis del documento presentaremos una descripción de las distintas partes en el que se puede organizar, aludiendo a las fojas que comprenden y los títulos o subtítulos que integran.

\section{Fs 1-11.}

Contiene los elementos litúrgicos clave de la doctrina cristiana, que el usuario del volumen empleaba a diario en su tarea de evangelización.

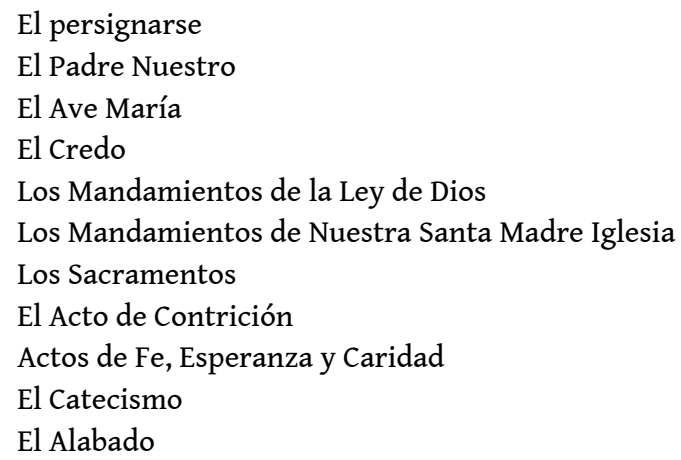

Los primeros acápites siguen muy cercanamente a Febrés, sin embargo se observa cierta reelaboración en algunos aspectos:

títulos: "El persignarse" (F.1) vs. "Por la Señal etc." (Febrés, 1765, p. 183); "Los sacramentos" (F. 4) vs. "Los sacramentos de la Santa Iglesia" (Febrés, 1765, p.187). Tampoco corresponden a Havestadt quien titula en latín "Per signum Crucis" (Havestadt, 1777, p. 539) y “Septem sacramenta” (Havestadt, 1777, p. 541).

omisión de secciones que aparecen en Febrés, Valdivia o Havestadt, como el Salve, los Artículos de la Fe, los Pecados mortales, las Bienaventuranzas, el rezo del Rosario, coplas para ser cantadas, etc.

En la misma sección, inserciones y variantes léxicas: “Amén Jesús, María y Joseph. Assí suelen concluir" (F.1) vs. “Amén Jesús, María, Joseph. Así suelen acabar” (Febrés, 1765, 
p.183); “Virgen Santa María ñi pue meu” (F.2, 'su vientre') vs “Virghen Santa María meu" (Febrés, 1765, p. 184; Valdivia, 1606, p.3; (Havestadt, 1777, p. 540).

En el siguiente texto, uno de los mandamientos de la Iglesia, sobre el mandato del ayuno en ciertos días prefijados, se observa que la variante sigue la versión de Valdivia para la ciudad de Imperial: "Meli dugu pi, Santa Ighlesia ñi thoquilelchi ayuan antú meu, ayunaiaymi." (F. 4) vs. "Meli dgu pij sancta Iglesia ni toquilelchi ayunan antu meu, ayunayaimi" (Valdivia 1606, p.8), "Meli dugu pi, Santa Ighlesia ñi thoquin antú meu, ayunayaymi." (Febrés 1765, p.186) y "Meli dugu pii: Santa Iglesia ni toquielchi ayunan antù ayunayaimi" (Havestadt 1777, p. 541).

Algunas divergencias gráficas: preferencia no sistemática por el grafema i en lugar de y: mleimi, ghùi (F.1), en lugar de muleymi, ghùy (Febrés 1765, pp. 183-184); uso de una marca de nasalisación junto al grafema g para señalar el sonido [ng], denotado en Febrés solo por g.

El cotejo con el catecismo de Febrés permite observar gran cantidad de similitudes en el interrogatorio y las respuestas, que remiten básicamente al credo católico. La comparación con otro catecismo, el Manual de Piedad, publicado en la ciudad de Concepción, área de evangelización franciscana, un siglo después del manuscrito que estamos analizando, nos ha permitido encontrar algunos contenidos que no aparecen en Febrés pero sí en estos dos textos: la descripción de la Eucaristía y los sacramentos de la confesión y la comunión, que se describen con detalle e insistencia.

Sólo una de las preguntas del catecismo de Orbanel no aparece en los otros dos catecismos que comparamos: “17. Una vez muerto nuestro Señor Jesucristo, fue enterrado?/ Sí, Padre”. Esto nos permite presuponer la vigencia del manuscrito de Orbanel en el área, como puente entre el catecismo jesuita de Febrés y el Manual de Piedad empleado a fines del siglo XIX.

Se titula Breve forma de Bautizar a los Indios adultos, y aporta una secuencia completa para la performance del sacramento, indicando al inicio del texto que dado que "los adultos deben responder a las preguntas pertenecientes al catecismo con el padrino, se pondrá aquí lo que debe hacer el misionero, y a que debe responder el indio en su idioma propio", en las siguientes situaciones:

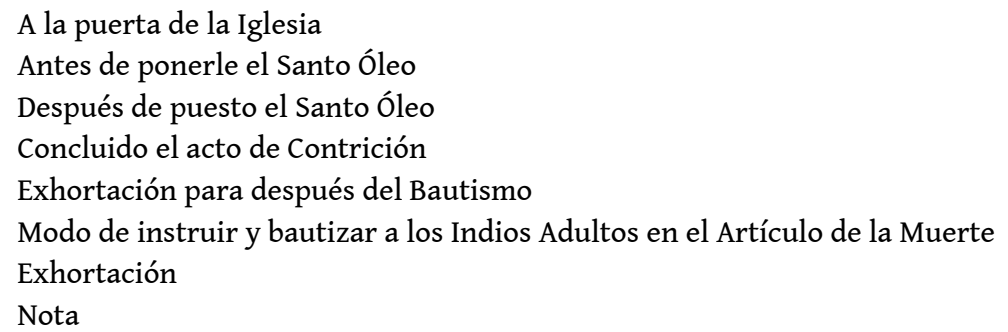

La nota final recuerda al sacerdote que esta misma fórmula puede ser empleada para la confesión de los indígenas que no hubieran recibido instrucción religiosa y se hallaren en trance de muerte. A pesar de las dificultades que conlleva se recomienda al misionero hacer el intento, ya que "la Gracia obra interiormente en el deseo que muestran de ser instruidos y de confesarse bien". Desde la perspectiva franciscana "puede esperarse que... tendrán delante de Dios mucha disculpa, así en su rudeza como en la ignorancia y brutalidad con que se criaron". El final del texto, con cambio de código al latín, 
fundamenta la idea desde el mandato expreso efectuado en ese sentido por el Concilio Limense.

Fs. 23-41.

En la Iglesia católica la confesión detallada y reiterada de los pecados constituye un sacramento ineludible para todo católico que quiera ser perdonado. Esta práctica se introdujo tempranamente en la evangelización americana para las poblaciones originarias, publicándose en el siglo XVI los primeros manuales de confesión bilingües. La base de la confesión era el Decálogo a modo de cuestionario. En el Reino de Chile el modelo utilizado fue el Confesionario para los curas de indios de 1585, fruto del III Concilio Limense, que el jesuita Luis de Valdivia adaptó al mapuzungun. Otros confesionarios jesuitas fueron publicados en 1765 por Andrés Febrés y en 1777 por Bernardo Havestadt. El Concilio señalaba que los curas confesores, antes de ser nombrados para la administración de este sacramento, debían ser examinados en la lengua indígena y en conocimientos de la moral. En el texto considerado, el Interrogatorio de la Confesión comprende una secuencia inaugural que se adapta a la primera confesión y a la propia de quien ya se habría acercado al sacramento. Luego, se encuentra un interrogatorio estructurado del primero al octavo mandamiento, con secciones especiales del cuarto y el sexto adaptados a las mujeres. La ausencia de los mandamientos noveno y décimo ya se registraba en Febrés, y en el Manual de Piedad estos se asimilan con el sexto y el séptimo. El confesionario presentado en Orbanel sigue las pautas propias de los textos jesuitas pero no copia literalmente ninguno de ellos.

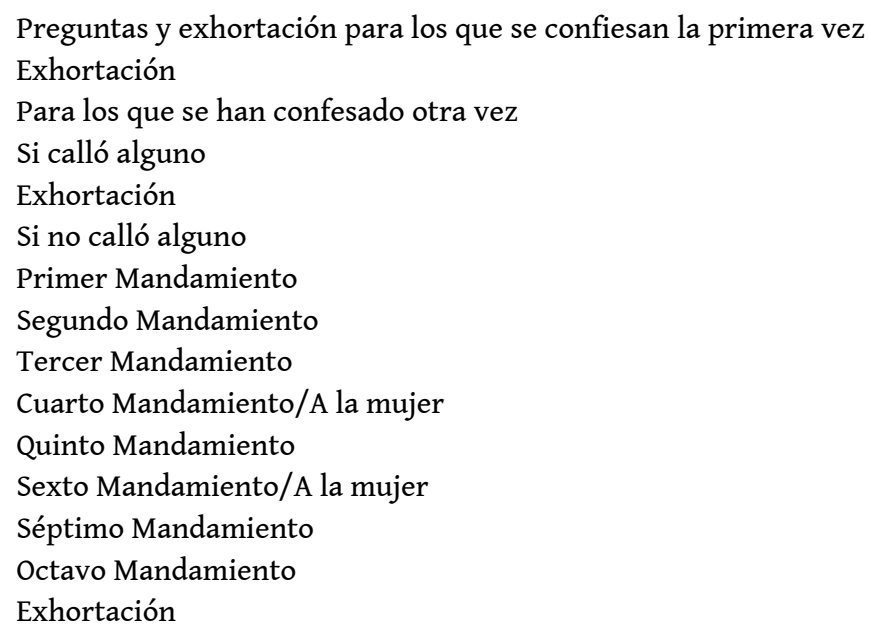

Para el área Pampa y Patagonia, el catecismo y confesionario de mayor circulación fue el de Febrés. Para el siglo XIX circulaba del otro lado de la cordillera un confesionario bilingüe escrito por el franciscano Fray Antonio Hernández Calzada (1843)(1907). En todos los casos es persistente la interrogación sobre prácticas culturales relacionadas con la práctica de machis, prácticas adivinatorias o propiciatorias y el ejercicio de las rogativas. En el confesionario de Hernández Calzada estas cuestiones se exacerban. Ya que el concepto de fondo de los confesionarios es la noción de pecado, ha sido bajo este rótulo donde se categorizaban tanto hábitos y prácticas culturales, entendidos y rechazados como supersticiones, como conductas sociales alejadas de los estándares morales de la sociedad occidental: mentir, matar, robar, etc. y otras que los sacerdotes no aceptaban, entre las que se destacan muy frecuentemente las relativas a las faltas al pudor (Nicoletti y Malvestitti, 2009b), o las que propiciaban la obediencia a las autoridades civiles, religiosas y militares reforzando el "pacto colonial". 


\section{Fs. 42-45. b}

Presenta una "Breve forma de administrar el sacramento del Matrimonio", desde las proclamas a la ceremonia en sí. Incluye los subtítulos: Proclamas

A la puerta de la Iglesia

Al Indio

Las velaciones se hacen conforme al Manual Mexicano hasta la entrega de las Arras, que entonces se dirá al esposo lo siguiente.

Responde la esposa

Para después del Ite Missa est leer desde el púlpito. Explica Durán que la Plática, que contenía la suma de lo que debía saber y hacer un cristiano, apuntaba a "provocar en la conciencia del auditorio una actitud profunda de conversión, la cual consistirá en el abandono de las antiguas creencias y prácticas culturales heredadas de sus antepasados, y en la aceptación de los contenidos dogmáticos y las exigencias morales de la nueva fe que se les predica" (Durán, 1982, p. 297). Para ello, el predicador partía de expresar su amor a los destinatarios de la Plática, y solicitaba "que ellos presten la máxima atención al mensaje que se les va a dirigir; porque él está relacionado con su propia salvación. Por esta razón el doctrinero inicia su catequesis diciendo: 'Óyeme hijo mío con atención, y decirte he brevemente lo que te conviene saber para salvarte'. Inmediatamente continúa con la narración de los principales aspectos del misterio cristiano" (Duran, 1982, p. 297).

En el texto de Orbanel las Pláticas exponen tópicos diversos. Las primeras se atienen a la estructura del Credo, deteniéndose en la explicación de los aspectos centrales de la religión (creación del mundo; Dios uno y trino; Encarnación y Pasión de Jesucristo; Juicio Final y destino de justos y pecadores). Luego, devienen en una presentación de los mandamientos, en la que aparecen expuestas con mayor visibilidad las faltas que develaban a los misioneros: la embriaguez, las faltas a la moral sexual y la circulación reparadora de elementos robados. Es decir, se apunta al cambio de prácticas sociales inaceptables para la Iglesia.

Primera plática. Para cuando entra el misionero la primera vez

Plática segunda. De la unidad de Dios

Plática tercera. Del fin para el que Dios crió el cielo y de la creación de los ángeles

Plática cuarta. De los misterios de la Santísima Trinidad y Encarnación del Hijo de

Dios

Plática quinta. Del fin que tuvo Jesucristo al hacerse hombre y del pecado original

Plática sexta. Del nacimiento, vida y muerte de Jesucristo, redentor nuestro

Plática séptima. De la muerte

Plática octava. Del juicio

Plática nona. Del infierno

Plática décima. Del misterio de la Santísima Trinidad para después de haber

cumplido con la Iglesia o que faltan pocos

Plática undécima. De la borrachera

Plática duodécima. Primer mandamiento de la Ley de Dios

Plática trece. De la Esperanza y Caridad

Plática catorce. Del segundo mandamiento 
Plática 15. Del tercer mandamiento

Plática 16. Del cuarto mandamiento

Plática 17. Del quinto mandamiento

Plática 18. Del sexto mandamiento (Simple fornicación, Adulterio, Estupro, Estupro

y Rapto, Sacrilegio)

Plática 19. Del sexto mandamiento (Sodomía, Bestialidad)

Plática 20. Del sexto mandamiento

Plática 21. Del séptimo mandamiento (Restitución, Ejemplo)

Plática 22. Del octavo mandamiento

51 Para su confección, el texto franciscano se basó, a veces de modo literal, en textos previos, en su mayoría bilingües mapuzungun-español. En Febrés (1765, pp. 380-439) se habían publicado cuatro pláticas (De Dios y la creación del mundo; De la Santísima Trinidad y Encarnación del Hijo de Dios; De la vida y muerte de Jesucristo al hacerse hombre y del pecado original; De la muerte y el infierno). Valdivia, por su parte había publicado previamente, en 1621, nueve, reimpresas como Nueve Sermones en lengua de Chile en 1897. Estas se titulan: De la inmortalidad del alma etc.; De la gravedad del pecado etc.; Del remedio que Dios trazó para el pecado, que fue la Encarnación; De la necesidad de la fe en Jesucristo para salvarnos; De cómo hay dios uno y trino; De cómo crió Dios el cielo y en él los ángel; De la creación y pecado del hombre; De la fundación de la Iglesia de Cristo; De la necesidad de la penitencia y sacramentos. En Havestadt (1777, pp. 545-566) aparecen cuatro sermones, y Medina menciona otras pláticas redactadas a mediados del siglo XVII, como las Pláticas doctrinales en forma de coloquios, compuestas en idioma chiliduxu por el P. Pedro Torrellas (Medina, 1897, p. XIII). La extensión de esta comunicación no nos permite extendernos en este punto, que podrá ser provechosamente profundizado a partir de la difusión de la fuente. en el análisis. Nuestras investigaciones previas pusieron de manifiesto redes intertextuales en los materiales de evangelización que circularon en territorio mapuche en ambos lados de la cordillera. Este texto funge como uno de los eslabones faltantes de una cadena catequística con escasa presencia franciscana. Desde el punto de vista lingüístico la elección del grafema v en las transcripciones estaría aludiendo a una de las variantes dialectales propias de los grupos pehuenche, destinatarios de la evangelización del área franciscana de Concepción. 
sacramentos señalamos: el bautismo, la confesión, el matrimonio y la extremaunción. En la celebración de la Misa cobran importancia significativa las pláticas cuyo objetivo era el de inducir la aceptación de nuevas conductas. Las explicaciones detalladas nos permiten advertir la importancia que los franciscanos le otorgaron al adoctrinamiento ajustado al dogma en el proceso de "conversión" para la aceptación de la nueva Fe.

Ya que el texto no es impreso como lo fueron los catecismos jesuitas, su circulación fue reducida pero esto no implica que no pudiera haberse replicado en otros ámbitos, por otros misioneros y en otras instancias evangelizadoras en la región. La bibliografía alude a muchos materiales de este tipo extraviados o quemados, afortunadamente este manuscrito ha sido conservado adecuadamente en un repositorio que permite su consulta y acceso.

\section{Anexo 1. Versión al español del catecismo ${ }^{19}$}

1. ¿Existe [es] Dios?/ Sí, Padre.

2. ¿Cuántos dioses hay?/ Un Dios solamente.

3. ¿Dónde está Dios?/ En el cielo, en la tierra, en toda la tierra está Dios.

4. ¿Quién es Dios?/ Dios Padre, Dios Hijo, Dios Espíritu Santo, tres personas, un Dios solamente.

5. ¿Dios Padre es Dios?/ Sí, Padre.

6. ¿Dios Hijo es Dios?/ Sí, Padre.

7. ¿Dios Espíritu Santo es Dios?/ Sí, Padre.

8. ¿Cuántos Dios [son] estos?20/ Un Dios solamente.

9. ¿Cuántas Personas?/ Tres Personas.

10. ¿Cuál de las tres Personas se hizo gente acá por nuestra causa ${ }^{21}$ (por nosotros)?/ Dios Hijo.

67 11. ¿En quién se hizo hombre acá? / En el vientre de [la] Virgen Santa María, por voluntad del Espíritu Santo.

12. Ya hecho hombre Dios Hijo, se llamó Señor Jesucristo?/ Sí, Padre. persona?/ Sólo en su ser persona.

14. ¿[Es] persona de verdad ${ }^{22}$ también nuestro Señor Jesucristo?/ Sí, Padre.

15. ¿Qué hizo nuestro Señor Jesucristo por causa de todos nosotros?/ Murió en una cruz.

16. ¿Cómo murió nuestro Señor Jesucristo, sólo en su ser Dios, o acaso sólo en su ser 17.Una vez muerto nuestro Señor Jesucristo, fue enterrado?/ Sí, Padre.

18. ¿Resucitó (también) nuestro Señor Jesucristo?/ Sí, Padre.

19.¿En cuántos días resucitó?/ En tres días.

20.Ya resucitado nuestro Señor Jesucristo, a qué tierra se dirigió?/ Al cielo.

21. ¿Va a volver a nuestra tierra otro día?/ Sí, Padre.

22.¿Cuándo va a volver?/ Cuando se termine esta tierra. 
23.¿Qué va a hacer de nuevo acá?/ Va a interrogar a la gente viva y a la gente muerta, a las buenas y malas personas también.

24. ¿Somos alma?/ Sí, Padre.

25. ¿Muere nuestra alma?/ No, Padre.

26.¿Qué muere de nosotros?/ Nuestro cuerpo solamente.

27. ¿El cuerpo de todos nosotros va a morir? / Sí, Padre.

28.¿Va a revivir nuestro cuerpo, una vez muerto?/ Sí, Padre.

29.¿Cuándo va a revivir?/ Cuando se termine esta tierra.

30.Una vez revivido nuestro cuerpo, el año que [todo haya] terminado todo va a revivir?/ Sí, Padre.

31. ¿Las personas buenas cuando mueran, dónde van a ir?/ Al cielo, donde no se va a terminar su gozo, su alegría, su buena vida tampoco.

32.¿Las personas malas cuando mueran, dónde van a ir?/ Al infierno [tierra del fuego], donde no se termina su quemarse, su estar ardiendo (de calor), su mala vida tampoco.

33. ¿El que no es cristiano, va a ir también a la tierra de Dios?/ No, Padre.

34.Si fueran cristianos, ¿querrían no estar junto a Dios [cortado]? / Al infierno donde no se termina su quemarse, su estar ardiendo (de calor), su mala vida tampoco.

35.El que es cristiano, el que sigue bien el mandamiento de Dios, una vez muerto, ¿dónde va a ir? / A la tierra de Dios, donde no se va a terminar su gozo, su alegría, su buena vida tampoco.

36.¿Por mandato ${ }^{23}$ de quién subirán las personas buenas al cielo, bajarán las malas al infierno?/ Por voluntad de Dios.

37.¿Por mandato de quién vive la gente, sufre la gente, muere la gente, va a resucitar la gente también?/ Por voluntad de Dios.

38. ¿Sol, luna, estrella, lucero, sapo dueño de agua, trueno, rayo es Dios?/ No, Padre.

39. ¿Qué [son] todos esos?/ Lo que Dios dejó, lo que Dios hizo, para que toda la gente esté bien.

40.Cuando el Padre levanta con/en su mano en la mitad de la misa, eso que es redondo, que es puro, llamado Hostia, esa es la vida ${ }^{24}$ de Dios, Cáliz se llama. ¿Quién está en la Santa Hostia, en ese Santo Cáliz también? / Nuestro Señor Jesucristo.

41.¿Entonces está el cuerpo de nuestro Señor Jesucristo, (esa) su sangre, (ese) su ser Dios, (ese) su ser persona? / [cortado]

42.(En) ese pequeño círculo puro para comulgar en la Iglesia, ¿quién está25?/ Allí está el cuerpo de nuestro Señor Jesucristo, (esa) su sangre, (ese) su ser Dios, (ese) su ser persona? 43.Quien tiene pecado, ¿podrá recibir ${ }^{26}$ al Señor Jesucristo?/ No, Padre.

44.¿Qué hará una persona para librarse de sus pecados?/ Se va a confesar con (el) Padre [en la] Misa.

45.¿Cómo se confesará bien?/ Primero, recordará todo su pecado, lo sacará ante (el) Padre, no va a esconder ninguno tampoco, [cortado] por causa de todo su pecado, que ya no va a pecar más, va a decir con/en su corazón. 


\section{BIBLIOGRAPHY}

Boccara, G. (2003). Los vencedores, historia del pueblo mapuche en la época colonial. Santiago de Chile: IAM.

Casanova Guarda, H. (1988). Presencia franciscana en la Araucanía. Las misiones del Colegio de Propaganda Fide de Chillán, 1756-1818). En J. Pinto Rodríguez (ed), Misioneros en la Araucanía 1600-1900, (pp. 121-197). Temuco: Universidad de la Frontera.

Durán, J. G. (1982). El catecismo del III Concilio Provincial de Lima y sus complementos pastorales (1584-85). Estudios preliminares, textos, notas. Buenos Aires: El derecho.

Durán, J. G. (1990). Monumenta Catechetica Hispanoamericana (siglos XVI-XVIII). Buenos Aires: Universidad Católica Argentina.

Durán, J. G. (1997). Catecismos pampas (1870-1885). Circunstancias históricas y alcances pastorales. Revista Teología, 69, (1), 5-69.

Farías, I. (2006). Misión franciscana del Río IV. Su influencia en la Villa de la Concepción del Río IV y la región pampeana. Revista Tefros, 4 (1), http://www.tefros.com.ar/revista/v4n1i06/notas/ farias.pdf

Febrés, A. (1765). Gramática Araucana o sea de la Lengua General de los Indios de Chile. Lima: s/d. García y García, A. (1986). La Reforma del Concilio III de Lima. En L. Pereña (Ed.) Doctrina Cristiana y Catecismo para instrucción de indios, (pp. 165-226). Madrid: CSIC.

Havestadt, B. (1777). Chilidugu sive Tractatus Linguae Chilensis. Westfalia: s/d.

Hernández Calzada, A. (1907 [1843]). Confesionario por preguntas y pláticas doctrinales en castellano araucano. Santiago: F. Becerra M. editor.

Corpus, Vol 2, No 2 | 2012 
Hux, M. (2000). El indio en la llanura del Plata. Guía bibliográfica. Buenos Aires: Asociación Amigos de las Artes Tradicionales, tomos I-II.

Medina, J. T. (1897). Prólogo. En L. de Valdivia, Nueve Sermones en lengua de Chile (pp. vii-xvi). Santiago de Chile: Imprenta Elseviriana.

Mitre, B. (1909). Catálogo razonado de la sección Lenguas americanas. Buenos Aires: Imprenta de Coni Hermanos, tomos I-III.

Nicoletti, M. A. y Malvestitti, M. (2009a). Catecismos mapuche y evangelización en la época del awkan: prédica misionera relaciones intertextuales. Revista de Estudios Trasandinos, 15, volumen 1, pp. 5-26.

Nicoletti, M. A. y Malvestitti, M. (2009b). Ñamünwerinpeyüm/ 'Para borrar los pecados': los Confesionarios para la evangelización en territorio mapuche. XII Jornadas Interescuelas/ Departamentos de Historia. Bariloche: Departamento de Historia, Universidad Nacional del Comahue, edición en CD-ROM.

Pérez Zavala, G. (2005). Oralidad y escritura: los tratados de paz entre el estado argentino y las tribus ranqueles. Tefros, 3, (1). http://www.unrc.edu.ar/publicar/tefros/revista/v3n1p05/ zabala.pdf

Pinto Rodríguez, J. (ed.) (1988). Misioneros en la Araucanía 1600-1900. Temuco: Universidad de la Frontera.

Pinto Rodríguez, J. (1993). Misioneros italianos en la Araucanía, 1600-1900. En B. Estrada (Ed), Presencia Italiana en Chile, (pp. 38-47). Valparaíso: Ediciones Universitarias de Valparaíso.

Racedo, E. (1965). La Conquista del Desierto. Memoria militar y decriptiva de la $3^{a}$ División Expedicionaria. Buenos Aires: Ediciones Pampa y Cielo.

Salas, A. (1992). Lingüística mapuche. Guía bibliográfica. Revista Andina, año 10, (2), pp. 10-15. Saranyana, J. (Dir.) (2005). Teología en América Latina. Escolástica barroca. Ilustración y preparación para la independencia (1665-1810). Madrid/Frankfurt: Iberoamericana-Vervuert.

Tamagnini, M. y Pérez Zavala, G. (2011). La "gran frontera" del Cono Sur: violencia y conflicto interétnico. En P. Navarro Floria y W. Delrio (Comps), Cultura y espacio. Araucanía-Norpatagonia, (pp. 208-221). Bariloche: IIDyPca, UNRN.

Valdivia, L. de (1684 [1606). Arte, vocabulario y confesionario de la lengua de Chile. Lima, s/d.

Valdivia, L. de (1897 [1621]). Nueve Sermones en lengua de Chile. Santiago de Chile: Imprenta Elseviriana.

Valdivia, L. de (1899). Manual de Piedad en castellano y en mapuche (araucano) para texto de lectura de los indígenas de Chile. Santiago de Chile: Imprenta de San José.

\section{NOTES}

1. Muestra de ello dan los Confesionarios que en algunos de sus títulos tratan sobre las "supersticiones de los indios", la "instrucción contra las ceremonias y ritos de los indios" y los "errores y supersticiones de los indios" (Ver Nicoletti y Malvestitti, 2009b).

2. Quien impulsó este Concilio y ordenó redactarlo e imprimirlo fue Santo Toribio Alfonso de Mogrovejo. La traducción al quechua y aymara fue realizada por un equipo de traductores, revisores, censores y consultores nombrados por el concilio "ad hoc". Sus catecismos fueron oficiales y canónicamente obligatorios para misioneros y párrocos (Durán 1982). 
3. Tanto jesuitas como franciscanos bebieron en distintas fuentes pastorales para encauzar el problema en concreto del bautismo con o sin adoctrinamiento previo y la implicancia que éste contenía respecto de la salvación y conversión del indígena: De procuranda indorum salute (1576) de José de Acosta los jesuitas y El Itinerario (1574) del franciscano Focher (Saranyana 2005, p. 226). 4. Los capuchinos bávaros llegaron posteriormente, en 1885 , desplazando a los italianos que habían arribado con el padre Lonigo en 1848.

5. La misma había sido reeditada pocos años antes. Según Salas (1992), “en 1846 apareció en Santiago una versión 'adicionada i correjida' del Arte y del Calepino (diccionario) del P. Febrés, preparada por el franciscano español Antonio Hernández Calzada, y realizada al cuidado de su co-hermano, el P. Mi chileno para su uso en el servicio de las misiones. (...) Tuvo gran demanda por lo cual se debió publicar en Concepción, en la Imprenta de la Unión, 1864, una versión resumida de la parte gramatical, sin el diccionario, prologada por Guillermo E. Cox. (...) Al decir de Tomás Guevara en su Historia de la Civilización de La Araucanía, la versión de Febrés revisada por el P. Hernández Calzada es 'un excelente tratado magistral del araucano y ha sido a la verdad el más generalizado en la Araucanía por los misioneros, militares y los indios que han sabido leer' " (Salas, 1992).

6. Pedro de Ángelis (Nápoles, 1784-Buenos Aires, 1859) fue historiador. Llevó adelante una importante tarea de recopilación y edición de documentos de Historia argentina. Pedro de Ángelis: Colección de Obras y Documentos relativos a la Historia Antigua y Moderna de las Provincias del Río de la Plata (1836), para ejemplificar su labor como recopilador y difusor de documentos históricos.

7. Literalmente "pertenece al uso".

8. Fray Pedro Ángel de Espiñeira (Galicia, 1727-Chile, 1778) profesó en la Orden en 1743, llega al Perú en 1752 y a Chillán en 1757. Mediante un sorteo le tocó asumir la misión entre los pehuenches. Después de dos misiones fue elegido guardián del Colegio de Chillán y en 1763 obispo de Concepción. Dentro de su labor pastoral se preocupó por el comercio clandestino de vino y ganado, visitó todo el territorio de su diócesis y se ocupó de los jesuitas expulsos enfermos y de las misiones que estos dejaron. Tuvo un papel protagónico en el Concilio Limense. Fray Pedro Ángel de Espiñeira incursionó en tierras pehuenches e intentó fundar la misión "Santa María del Pilar" (actual Guañacos, Neuquén), que fue vértice de un proyecto misionero que conformó un triángulo cuyas bases se asentaron en Chillán y en Santa Bárbara, esta última como puerta para la penetración en tierras neuquinas. Desde Santa Bárbara como base y primera misión, "Santa María del Pilar" quedaba enmarcada en un proyecto que incluía al sur del Bío Bío las misiones de Nuestra Señora de la Concepción (valle de Rucahué) y Nuestro Padre San Francisco de Lonco (río Malleco), destruidas en el levantamiento de 1769. Fray Espiñeira relató su viaje de misión (Pinto Rodríguez, 1988).

9. Se lo denomina a San Francisco como santo seráfico pues fue un serafín (son los primeros de los ángeles cuya función es estar en perpetua alabanza a Dios), quien le imprimió el estigma (las heridas de la Pasión de Cristo) en su cuerpo.

10. La orden franciscana fue aprobada por el Papa Inocencio III en 1209. Las divisiones internas se produjeron de acuerdo a los diferentes modos de vivir y observar la Regla de San Francisco de Asís, sobre todo en relación a la pobreza, carisma central de la orden. En 1517 el Papa León X dividió la Orden entre dos ramas: Conventuales y Observantes y en 1535 dentro de los Observantes se inició el movimiento de la Reforma Capuchina. Esta rama buscó una vida más contemplativa, se separaron de los observantes, retomaron el hábito original de San Francisco y son la única división de los observantes que permaneció independiente.

11. Se observa también una doble catalogación bibliográfica, 14-3-23, luego 14-1-33, y dos números de inventario: Doc. 3916 y 4151; el último es el actual.

12. Adjutorium nostrum in nomine Domini (Battiston y Domínguez, c.p.)

13. qui fecit caelum et terram (Battiston y Domínguez, c.p.) 
14. Abreviatura de Domine (Battiston y Domínguez, c.p.)

15. “Señor, ten piedad". Expresión griega muy antigua, incluso pre-cristiana; traducida al latín es el nombre de una oración utilizada constantemente en todas las liturgias cristianas (Battiston y Domínguez, c.p.)

16. Et ne nos inducas in tentationem (Battiston y Domínguez, c.p.)

17. Sed libera nos a malo. (Battiston y Domínguez, c.p.)

18. Et cum spirito tuo (Battiston y Domínguez, c.p.)

19. Traducción del mapuzungun de Marisa Malvestitti.

20. La traducción literal, de modo similar a la proposición 2, sería “¿cuánto dios este?”, o sea no hay marcas de plural ni en el verbo ni en la frase nominal.

21. ñi vla aparece en el Catecismo y Pláticas de Febrés (hay que chequear en los demás). Es una frase hecha y a veces con concordancia errónea (por ej., inchiñ taiñ ñivla- ñi está de más).

22. El autor usa siempre che 'persona, gente', no usa wentru 'hombre'.

23. thoquiel ' mandato, voluntad, mandamiento'.

24. entendemos que así podría traducirse la palabra liwe.

25. permanece, habita, hay.

26. traqn 'pasar algo a otra mano'.

27. Esta expresión aparece en Febrés.

\section{ABSTRACTS}

The Doctrina cristiana, catecismo, forma de administrar los sacramentos con 22 pláticas en araucano by Fray Serviliano araucano Orbanel (circa 1778) whose manuscript is in the Mitre Museum Archive (CABA), is an unpublished document that we make available to the public. This manuscript belonging to the Franciscan Order was a sort of manual to evangelize the Mapuche people in the eighteenth century in their own language. Those catechetical texts in mapuzungun, Spanish and Latin helped the missionary to transmit the doctrine, administer the sacraments, preach and teach prayers. The catechism by Fray Orbanel is one of the few texts of the Franciscan order of these features, as mostly belong to the Society of Jesus, jesuits, source of much of the bilingual catechisms circulated during colonial and national evangelization.

La Doctrina cristiana, catecismo, forma de administrar los sacramentos con 22 pláticas en araucano compuesta por Fray Serviliano Orbanel (circa 1778) cuyo manuscrito se encuentra en el Archivo del Museo Mitre (CABA), constituye una fuente inédita que ponemos a disposición de los lectores. Este manuscrito del siglo XVIII perteneciente a la orden franciscana fue una suerte de manual para evangelizar al pueblo mapuche en su propia lengua. Tal conjunto de textos catequísticos ayudaba al misionero a transmitir la doctrina, administrar los sacramentos, enseñar las oraciones y predicar, y fue redactado en mapuzungun, español y latín. El catecismo de Fray Orbanel es uno de los pocos textos de la orden franciscana de estas características, ya que su mayoría pertenecen a la Compañía de Jesús, fuente de gran parte de los catecismos bilingües que circularon durante la evangelización colonial y de los estados nacionales. 
INDEX

Keywords: Evangelization, Mapuche, Franciscans, Catechisms

Palabras claves: Evangelización, Franciscanos, Catecismos

\section{AUTHORS}

\section{MARISA MALVESTITTI}

IIDyPCa/Universidad Nacional de Río Negro, Argentina. Correo electrónico: malves.marisa@gmail.com

\section{MARÍA ANDREA NICOLETTI}

Consejo Nacional de Investigaciones Científicas y Técnicas (CONICET) - IIDyPCa/ Universidad Nacional de Río Negro, Argentina. Correo electrónico: mariaandreanicoletti@gmail.com 